\title{
Conteúdo Corporal e Exigências Líquidas de Proteína e Energia de Novilhos Suplementados no Período das Águas 1
}

\section{Joanis Tilemahos Zervoudakis ${ }^{2}$, Mário Fonseca Paulino ${ }^{3}$, Edenio Detmann ${ }^{4}$, Sebastião de Campos Valadares Filho $^{3}$, Rogério de Paula Lana ${ }^{3}$, Paulo Roberto Cecon ${ }^{5}$, Domingos Sávio de Queiroz ${ }^{6}$, Andréia Luciane Moreira ${ }^{7}$}

\begin{abstract}
RESUMO - Avaliaram-se os efeitos da suplementação concentrada de novilhos, durante o período das águas, sobre os conteúdos corporais de proteína e energia e as respectivas exigências líquidas para ganho de peso. Foram utilizados 49 novilhos mestiços, mantidos em pastagem de Brachiaria decumbens. O experimento foi conduzido em três períodos experimentais, segundo delineamento inteiramente casualizado. Foram fornecidos diariamente sal mineral (SAL), suplementos à base de milho e farelo de soja, com $20 \% \mathrm{~PB}$, em nível de 1,0 e 2,0 kg/dia (MFS1 e MFS2), respectivamente, e suplementos à base de farelo de trigo e farelo de soja, com $20 \%$ PB, em nível de 1,0 e 2,0 kg/dia (FTFS1 e FTFS2), respectivamente. Não foram encontradas diferenças entre os tratamentos sobre os conteúdos corporais de proteína e energia para os tratamentos SAL, MFS1, MFS2, FTFS1 e FTFS2. Os animais submetidos aos diferentes tratamentos não exibiram diferenças na composição do ganho de peso para proteína, gordura e energia. As exigências líquidas de proteína e energia para um animal de $350 \mathrm{~kg}$ de peso vivo foram, respectivamente, de $220 \mathrm{~g}$ e 5,75 Mcal por $\mathrm{kg}$ ganho de peso vivo.
\end{abstract}

Palavras-chave: conteúdo corporal, exigências nutricionais, suplementos, pastagem

\section{Body Composition and Net Requeriments of Energy and Protein of Supplemented Steers during the Rainny Season}

\begin{abstract}
The effects of concentrate supplementation of stocked an during the rainny season on the body composition of energy and protein and net requirements of protein and energy for weight gain were evaluated. Forty-nine crossbred steers, were Brachiaria decumbens pastures, were used. The experiment was driven in three experimental periods, according to a completely randomized design. The following supplements were daily fed at 10 a.m.: mineral salt (SALT), supplements based on corn and soybean meal, with $20 \%$ $\mathrm{CP}$, at the level of 1.0 and $2.0 \mathrm{~kg}$ (CSBM1 and CSBM2) and supplements based on wheat bran and soybean meal, with $20 \% \mathrm{CP}$, at the level of 1.0 and $2.0 \mathrm{~kg}$ (WMSBM1 and WMSBM2). The animals submitted to the different treatments showed no differences on composition of weight gain in the protein, fat and energy. The net requirements of protein and energy for an animal with 350 of body weight were, respectively, $220 \mathrm{~g}$ and $5.75 \mathrm{Mcal}$ per $\mathrm{kg}$ of live weight gain.
\end{abstract}

Key Words: body composition, grazing, net requeriments, supplements

\section{Introdução}

Dentro de uma perspectiva ecológica, a obtenção de um produto animal a partir de forragens envolve a produção da planta, sua conversão para produto, a eficiência de conversão e seu valor econômico dentro dos limites das barreiras ecológicas. $\mathrm{O}$ animal em pastejo se insere em um ciclo que se altera dinamicamente, influenciado pelo ambiente e por mudanças nos requerimentos e no suprimento de forragem (Noller et al., 1996).

A qualidade da forragem pode ser determinada em termos do desempenho animal obtido quando esta forragem é fornecida ao animal (Penati et al., 1999). O desempenho animal é função do consumo de nutrientes digestíveis e metabolizáveis. Da variação existente no consumo da matéria seca (MS) digestível ou da energia digestível, entre animais e alimentos, 60 a 90\% estão relacionados ao consumo de MS e apenas 10 a $40 \%$, às diferenças na digestibilidade (Mertens, 1994).

Na intensificação do processo produtivo, visando à pecuária de ciclo curto, os principais aspectos a serem considerados no estabelecimento de padrões de crescimento para os animais são idade ao primeiro parto para as fêmeas e idade ao abate para os

\footnotetext{
${ }_{1}$ Parte da tese do primeiro autor, apresentada à Univ. Fed. de Viçosa, para obtenção do título de Magister Scientiae em Zootecnia.

2 Zootecnista, MS, Estudante de Doutorado, DZO-UFV, Viçosa-MG, 36571-000. E.mail: joanis@alunos.ufv.br

3 Professor do Departamento de Zootecnia, Univ. Federal de Viçosa, Pesquisador do CNPq, Viçosa-MG, 36571-005.

4 Zootecnista, DS, DZO-UFV, Viçosa-MG, 36571-000.

5 Professor do Departamento de Informática, Univ. Federal de Viçosa, Viçosa-MG, 36571-005.

6 Pesquisador da EPAMIG, Viçosa - MG - CEP 36571-000

7 Zootecnista, MS, Estudante de Doutorado, UNESP, Jaboticabal.
} 
machos. Dentro desse enfoque, qualquer tentativa de exploração da precocidade em bovinos está intimamente relacionada à melhoria das condições alimentares, principalmente durante o período seco do ano (Paulino, 1998).

Observa-se, entretanto, que níveis superiores de desempenho animal nem sempre são encontrados quando somente a forragem é consumida. Melhorar o desempenho de bovinos consumindo forragens com conteúdo moderadamente alto de proteína pode requerer o uso de suplementos energéticos (Hess et al., 1996).

Entretanto, devido às interações existentes entre a forragem e o suplemento, grandes variações no consumo de forragem e produção animal podem ocorrer. Dessa forma, fazem-se necessários maiores estudos nesta área, para reduzir as incertezas e os resultados contraditórios existentes em programas de suplementação a pasto.

No Brasil, a exigência nutricional de bovinos em pastejo tem sido pouco estudada; para cálculos de rações e suplementos, têm sido freqüentemente utilizadas as normas internacionais de alimentação, como ARC (1980; 1984), NRC $(1984 ; 1996)$ e AFRC (1993). Entretanto, a eficiência na produção animal somente será alcançada se houver conhecimento adequado das exigências nutricionais dos animais, bem como da composição dos alimentos utilizados (Coelho da Silva, 1995), propiciando, dessa forma, predições mais precisas do desempenho dos animais. Nesse sentido, as exigências dos animais e o valor energético dos alimentos são informações fundamentais para se atingirem os objetivos acima.

Os objetivos do presente estudo foram avaliar a composição corporal e estimar as exigências de energia e proteína para ganho de peso, na terminação de novilhos mestiços Holandês-Zebu castrados, mantidos em regime de suplementação concentrada a pasto no período das águas.

\section{Material e Métodos}

O presente estudo foi realizado na Fazenda Experimental de Felixlândia, da Empresa de Pesquisa Agropecuária de Minas Gerais (EPAMIG), em Felixlândia-MG, no período de janeiro e maio de 1998.

A cidade de Felixlândia está localizada a $18^{\circ} 45^{\prime} 42^{\prime \prime}$

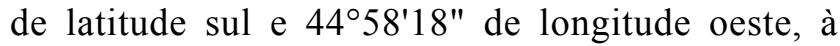
altitude de $616 \mathrm{~m}$. A temperatura média anual é de $22,0^{\circ} \mathrm{C}$, com média das máximas e mínimas de 27,9 e $14,9^{\circ} \mathrm{C}$, respectivamente. A precipitação média anual é de $1.200 \mathrm{~mm}$. O clima da região é classificado como Aw (tropical úmido), segundo classificação proposta por Köepen (1948).

A área experimental constituiu-se de cinco piquetes de oito hectares, com topografia plana, coberta uniformemente com a gramínea Brachiaria decumbens, divididos por cerca eletrificada, sendo providos de bebedouro e comedouro coberto.

Foram utilizados quarenta e nove animais mestiços Holandês-Zebu, castrados, com idade e peso médios iniciais de 18 meses e $278 \mathrm{~kg}$, respectivamente, originários da EPAMIG, sendo escolhidos em função do grau de sangue, da idade e do peso, dos quais quatro foram destinados ao abate inicial de referência e os demais, ao ensaio de desempenho.

Foram utilizados um brete, para contenção dos animais, e uma balança, para que se realizasse a pesagem dos mesmos a cada início e final de período experimental, sendo os mesmos rotacionados entre os piquetes a cada 28 dias.

Os animais remanescentes foram distribuídos em cinco lotes uniformes, quanto ao peso vivo e à condição corporal, e, posteriormente, designados, aleatoriamente, aos seguintes tratamentos:

T1 - controle, sem suplementação (SAL) (Salt);

T2 - suplemento constituído de milho e farelo de soja, fornecido em nível de $1 \mathrm{~kg} /$ dia (MFS1) (CSBM1);

T3 - suplemento constituído de milho e farelo de soja, fornecido em nível de $2 \mathrm{~kg} /$ dia (MFS2) (CSBM2);

T4 - suplemento constituído de farelo de trigo e farelo de soja, fornecido em nível de $1 \mathrm{~kg} / \mathrm{dia}$ (FTFS1) (WMSBM1);

T5 - suplemento constituído de farelo de trigo e farelo de soja, fornecido em nível de $2 \mathrm{~kg} / \mathrm{dia}$ (FTFS2) (WMSBM2).

Os suplementos foram previamente balanceados, em função dos valores de composição relatados por Campos (1995), objetivando atingir nível de $20 \%$ de proteína bruta $(\mathrm{PB})$, com base na matéria natural (Tabela 1), sendo fornecidos diariamente aos animais às $10 \mathrm{~h}$. Os animais em todos os tratamentos possuíam livre acesso à água e mistura mineral.

Procedeu-se ao abate de quatro animais (referência) no início do experimento e de três animais de cada tratamento no final do experimento, totalizando 19 animais abatidos, objetivando a determinação da 
Tabela 1 - Composição dos suplementos (\%), com base na matéria natural

Table 1 - Composition of supplements (\%), as fed basis

\begin{tabular}{|c|c|c|c|}
\hline \multirow[b]{2}{*}{$\begin{array}{l}\text { Ingrediente } \\
\text { Ingredient }\end{array}$} & \multicolumn{3}{|c|}{$\begin{array}{c}\text { Tratamento } \\
\text { Treatment }\end{array}$} \\
\hline & $\begin{array}{l}\text { SAL }^{1} \\
\text { Salt }\end{array}$ & $\begin{array}{c}\text { MFS1/ } \\
\text { MFS2 } \\
\text { CSBM1/ } \\
\text { WMSBM1/ }\end{array}$ & $\begin{array}{c}\text { FTFS1/ } \\
\text { FTFS2 } \\
\text { CSBM2 } \\
\text { WMSBM2 }\end{array}$ \\
\hline $\begin{array}{l}\text { Mistura mineral } \\
\text { Mineral premix }\end{array}$ & 100 & - & - \\
\hline $\begin{array}{l}\text { Milho grão } \\
\text { Corn grain }\end{array}$ & - & 67,6 & - \\
\hline $\begin{array}{l}\text { Farelo de trigo } \\
\text { Wheat meal }\end{array}$ & - & - & 83,3 \\
\hline $\begin{array}{l}\text { Farelo de soja } \\
\text { Soybean meal }\end{array}$ & - & 32,4 & 16,7 \\
\hline $\begin{array}{l}1 \text { Composição perce } \\
48,01 \text {; sulfato de } \\
\text { cobalto, } 0,05 \text {; e ioc } \\
1 \text { Percentage composit } \\
\text { zinc sulfate, } 1.50 \text {; co, } \\
\text { iodate, } 0.03 \text {. }\end{array}$ & $\begin{array}{l}\text { al: fosfato } \\
0,1,50 ; \\
\text { de potás } \\
\text { dicalcium } \\
\text { sulfate, } 0 \text {. }\end{array}$ & $\begin{array}{l}\text { álcico, } 50,01 \text {; } \\
\text { ato de cobre, } \\
0,03 \text {. } \\
\text { fate, } 50.01 \text {; sod } \\
\text { cobalt sulfate, }\end{array}$ & $\begin{array}{l}\text { eto de sódio, } \\
0 \text {; sulfato de } \\
\text { hloride, 48.01; } \\
\text { and potassium }\end{array}$ \\
\hline
\end{tabular}

composição física e química e das características das carcaças dos bovinos. Os abates ocorreram por concussão cerebral e posterior secção da veia jugular.

Os animais remanescentes submetidos ao ensaio de desempenho foram abatidos em média, com peso vivo em jejum de $409 \mathrm{~kg}$.

Logo após o abate de cada animal, foram pesadas e coletadas amostras de sangue, couro, cauda, aparelho reprodutor, rúmen-retículo, omaso, abomaso, intestino delgado, intestino grosso, mesentério, gordura interna, carne industrial, fígado, coração, rins, pulmões, traquéia, baço, língua e esôfago. Para um animal abatido de cada tratamento, foram pesadas, dissecadas e retiradas amostras de uma cabeça e um pé.

Coletou-se uma amostra representativa da meiacarcaça esquerda, correspondendo à seção da $9^{a}$ à $11^{\text {a }}$ costela (seção $\mathrm{HH}$ ), de acordo com Hankins \& Howe (1946), objetivando posteriores dissecações, avaliações dos componentes físicos (músculo, tecido adiposo e ossos) e químicos (teores de proteína e gordura) das carcaças.

Amostras com, aproximadamente, $1 \mathrm{~kg}$ de todos os suplementos foram coletadas a cada preparo das misturas, que foram homogeneizadas, para obtenção da amostra composta de todo o período experimental, e, posteriormente, armazenadas para futuras análises laboratoriais no Departamento de Zootecnia, com relação aos seus teores de matéria seca (MS), proteína bruta (PB), cinzas, extrato etéreo (EE), segundo metodologia descrita por Silva (1990). A determinação dos teores de fibra em detergente neutro (FDN) foi feita segundo técnica descrita por Van Soest et al. (1991). Os carboidratos totais (CHOT) foram obtidos por intermédio da equação: $100-(\% \mathrm{~PB}+\% \mathrm{EE}+$ \%Cinzas) e os carboidratos não-estruturais (CNE), pela diferença entre CHOT e FDN (Sniffen et al., 1992). A composição bromatológica dos suplementos é mostrada na Tabela 2.

As amostras de fígado, coração, rins, pulmões, língua, traquéia, esôfago, carne industrial, baço e aparelho reprodutor foram agrupadas, proporcionalmente, de forma a constituírem amostras compostas de órgãos. Igualmente, as amostras de rúmen-retículo, omaso, abomaso, intestino delgado, intestino grosso, gordura interna e mesentério foram agrupadas proporcionalmente, constituindo-se amostras compostas de vísceras.

As amostras de couro, cauda e ossos (120 g), após seccionadas, e as amostras de carne (120 g), gordura $(200 \mathrm{~g})$, composta de vísceras $(200 \mathrm{~g}) \mathrm{e}$

Tabela 2 - Teores médios de matéria seca (MS), matéria orgânica (MO), proteína bruta (PB), extrato etéreo (EE), carboidratos totais (CHOT), fibra em detergente neutro (FDN), carboidratos nãoestruturais (CNE) e cinzas, com base na matéria seca para os suplementos à base de milho e farelo de soja (MFS 1 e 2) e farelo de trigo e farelo de soja (FTFS 1 e 2)

Table 2 - Average contents of dry matter (DM), organic matter $(O M)$, crude protein (CP), ether extract (EE), total carboydrate (TC), neutral detergent fiber (NDF), nonstructural carboydrate (NSC) and ash, based on dry matter of supplements including corn and soybean meal (CSBM 1 and 2) and supplements as wheat bran and soybean meal (WMSBM 1 and 2)

\begin{tabular}{lcc}
\hline Item & \multicolumn{2}{c}{$\begin{array}{c}\text { Suplemento } \\
\text { Supplements }\end{array}$} \\
\cline { 2 - 3 } & MFS & FTFS \\
& $C S B M$ & WMSBM \\
\hline MS $(D M), \%$ & 81,7 & 79,5 \\
MO $(O M)^{1}$ & 96,6 & 93,7 \\
PB $(C P)^{1}$ & 25,8 & 24,3 \\
EE $(E E)^{1}$ & 0,4 & 0,1 \\
CHOT $(T C)^{1}$ & 69,8 & 69,2 \\
FDN $(N D F)^{1}$ & 11,9 & 44,3 \\
CNE $(C N S)^{1}$ & 57,9 & 24,9 \\
Cinzas $(A s h)^{1}$ & 3,4 & 6,3 \\
\hline
\end{tabular}

$1 \% \mathrm{MS}(\% D M)$. 
composta de órgãos (200 g), após moagem, foram colocadas em vidros com capacidade de $500 \mathrm{~mL}$ e, posteriormente, levadas à estufa a $105^{\circ} \mathrm{C}$, durante um período de 72 a 96 horas, visando à determinação da matéria seca gordurosa (MSG).

Logo após a secagem, as amostras foram submetidas a um processo de extração da gordura, com o uso de éter de petróleo, conforme descrito por Kock \& Preston (1979), obtendo-se a matéria seca prédesengordurada (MSPD). Estas amostras foram, então, moídas em moinho de bola e armazenadas em vidros previamente identificados, com tampa de polietileno, para posteriores determinações dos teores de nitrogênio total e extrato etéreo.

As amostras de sangue, coletadas no momento do abate (400 g), foram acondicionadas em pratos de alumínio (marmitex) e levadas à estufa de ventilação forçada $\left(55-65^{\circ} \mathrm{C}\right)$, durante um período de 48 horas, para determinação da matéria pré-seca, sendo posteriormente moídas em moinho de bola e armazenadas em vidros para posteriores análises laboratoriais.

As proporções de músculo, tecido adiposo e ossos da carcaça foram estimadas com base nas proporções destes componentes na seção $\mathrm{HH}$, segundo as equações desenvolvidas por Hankins \& Howe (1946):

$\begin{array}{ll}\text { Músculo } & \hat{\mathrm{Y}}=16,08+0,80 \mathrm{X} \\ \text { Tecido adiposo } & \hat{\mathrm{Y}}=3,54+0,80 \mathrm{X} \\ \text { Ossos } & \hat{\mathrm{Y}}=5,52+0,57 \mathrm{X}\end{array}$

em que: $X$ é a porcentagem do componente na seção HH.

Os conteúdos corporais de proteína e gordura foram determinados em função dos pesos e das composições percentuais de cada parte do corpo do animal, cauda, couro, sangue, vísceras e órgãos, bem como das partes separadas, da carcaça (músculo, tecido adiposo e ossos) e de cabeças e pés (tecido adiposo e ossos).

O peso do corpo vazio (PCVZ) dos animais foi determinado pela soma do peso de carcaça, cabeça, couro, sangue, pés, cauda, órgãos e vísceras. Estabeleceu-se uma relação entre o peso do corpo vazio (PCVZ) e o peso vivo (PV) dos quatro animaisreferência, para ser utilizada na estimativa do PCVZ inicial dos animais abatidos no final do experimento.

O conteúdo corporal de energia foi determinado a partir dos conteúdos corporais de proteína e gordura e de seus respectivos equivalentes calóricos, conforme a equação abaixo (ARC, 1980):

$$
\widehat{\mathrm{CE}}(\mathrm{Mcal})=5,6405 \mathrm{X}+9,3929 \mathrm{Y}
$$

em que: $\widehat{C E}=$ conteúdo de energia; $\mathrm{X}=$ proteína corporal $(\mathrm{kg})$; e $\mathrm{Y}=$ gordura corporal $(\mathrm{kg})$.

Para predição dos conteúdos de proteína, gordura e energia retidos no corpo dos animais, adotou-se a equação de regressão do logaritmo do conteúdo corporal de proteína, gordura e energia, em função do logaritmo do peso do corpo vazio (ARC, 1980), conforme o seguinte modelo:

$$
\mathrm{Y}_{\mathrm{i}}=\mathrm{a}+\mathrm{bx}_{\mathrm{i}}+\mathrm{e}_{\mathrm{i}}
$$

em que: $Y_{i}=$ logaritmo do conteúdo total de proteína $(\mathrm{kg})$, gordura $(\mathrm{kg})$ e energia (Mcal) retido no corpo vazio; $a=$ constante; $b=$ coeficiente de regressão do logaritmo do conteúdo de proteína, gordura e energia em função do logaritmo do peso do corpo vazio; $\mathrm{x}_{\mathrm{i}}=\operatorname{logaritmo}$ do peso de corpo vazio; $\mathrm{e}_{\mathrm{i}}=$ erro aleatório.

$\mathrm{Na}$ determinação das equações de regressão, utilizou-se o programa SAEG (Sistema para análises estatísticas e genéticas), UFV (1995).

$\mathrm{O}$ fator de conversão de PV em PCVZ, para animais de diferentes pesos vivos, foi obtido pela regressão do quociente PV/PCVZ dos 19 animais abatidos do experimento, em função do PV dos mesmos.

As equações de predição das exigências líquidas de energia e proteína, para ganho de $1 \mathrm{~kg}$ de peso de corpo vazio (PCVZ), foram determinadas pela derivação das equações de predição do conteúdo corporal de proteína e energia, em função do logaritmo do PCVZ, obtendo-se equações do tipo:

$$
\mathrm{Y}^{\prime}=\mathrm{b} \cdot 10^{\mathrm{a}} \cdot \mathrm{x}^{(\mathrm{b}-1)}
$$

em que: $\mathrm{Y}^{\prime}=$ exigência líquida de energia (Mcal) ou proteína $(\mathrm{kg})$ para $1 \mathrm{~kg}$ de ganho de PCVZ; $\mathrm{b}=$ coeficiente de regressão do logaritmo do conteúdo de energia ou proteína, em função do logaritmo do PCVZ; a = intercepto; e $\mathrm{x}=$ PCVZ (kg).

Para conversão das exigências para ganho de PCVZ em exigências para ganho de peso vivo, utilizou-se o fator médio de 0,92 , obtido na equação de predição do $\mathrm{PCVZ}$, em função do PV, no presente estudo.

Para testar a identidade dos modelos aplicados às equações de regressão do logaritmo do conteúdo corporal de proteína, gordura e energia, em função do logaritmo do PCVZ para os diferentes suplementos estudados, utilizou-se o teste de identidade de modelos (Regazzi, 1993). 


\section{Resultados e Discussão}

Ajustou-se a equação de predição do peso corporal vazio a partir do peso vivo, em conjunto para todos os animais experimentais abatidos. Verificou-se efeito linear significativo $(\mathrm{P}<0,05)$ do peso corporal vazio (PCVZ), em função do peso vivo (PV) dos animais.

A equação obtida é apresentada abaixo:

$$
\widehat{P C V Z}=-93,4220+1,0912 \mathrm{PV}, \mathrm{r}^{2}=0,98
$$

O alto coeficiente de determinação obtido $\left(\mathrm{r}^{2}=0,98\right)$ na equação de predição do PCVZ a partir do PV evidencia o bom ajustamento da equação aos dados.

O peso corporal vazio de um animal com $400 \mathrm{~kg}$ de peso vivo $(343 \mathrm{~kg}$ ), estimado a partir da equação acima, foi 0,62\% superior ao obtido por Fontes (1995), com base em equação específica para mestiços, por intermédio de um conjunto de animais castrados e não-castrados, e 0,43 e $0,73 \%$ superior aos valores obtidos utilizando-se as equações de Jorge (1997) e Paulino (1996); respectivamente, todos os estudos foram conduzidos em condições de confinamento.

O teste de identidade de modelos (Regazzi, 1993) aplicado às equações de regressão do logaritmo do conteúdo corporal de proteína, gordura e energia, em função do logaritmo do PCVZ para os diferentes suplementos estudados, demonstrou não haver diferença entre os tratamentos; dessa forma, os conteúdos corporais de proteína, gordura e energia foram estimados porintermédio da equação geral comum a todos tratamentos (Tabela 3).

A ausência de diferenças significativas entre os tratamentos concorda com os resultados referentes à

Tabela 3 - Parâmetros da regressão do logaritmo do conteúdo corporal de proteína $(\mathrm{kg})$, gordura $(\mathrm{kg})$ e energia (Mcal), em função do logaritmo do peso corporal vazio (PCVZ), para novilhos mestiços castrados

Table 3 - Parameter of regression of log of body content of protein (kg), fat ( $\mathrm{kg}$ ) and energy (Mcal), on EBW log, for crossbreed steers

\begin{tabular}{lccc}
\hline $\begin{array}{l}\text { Componente } \\
\text { Component }\end{array}$ & \multicolumn{2}{c}{$\begin{array}{c}\text { Parâmetro da regressão } \\
\text { Parameter of regression }\end{array}$} & $\mathrm{r}^{2}$ \\
\cline { 2 - 3 } & $\begin{array}{c}\text { Intercepto } \\
\text { Intercept }\end{array}$ & $\begin{array}{c}\text { Coeficiente (b) } \\
\text { Coeficient (b) }\end{array}$ & \\
\hline $\begin{array}{l}\text { Proteína } \\
\text { Protein }\end{array}$ & $-0,7687$ & 1,026 & 0,74 \\
$\begin{array}{l}\text { Gordura } \\
\text { Fat }\end{array}$ & $-4,8952$ & 2,669 & 0,81 \\
$\begin{array}{l}\text { Energia } \\
\text { Energy }\end{array}$ & $-1,9077$ & 1,9515 & 0,88 \\
\hline
\end{tabular}

R. Bras. Zootec., v.31, n.1, p.530-537, 2002 (suplemento) composição física da carcaça dos animais experimentais, que não diferiram nas proporções estimadas de músculo, tecido adiposo e ossos.

Os coeficientes de determinação apresentados na Tabela 3 indicam bom ajustamento das equações aos dados experimentais e são similares aos obtidos por Lana (1991) e Paulino (1996), utilizando animais não-castrados em confinamento.

Os conteúdos corporais totais de proteína (PBT), gordura (GT), bem como os conteúdos de proteína, gordura e energia por quilograma de $\mathrm{PCVZ}$ e relação entre gordura e proteína (G/PB), estimados por meio das equações de regressão para animais com pesos vivos de 250 a $450 \mathrm{~kg}$, são apresentados na Tabela 4.

A relação G/PB indica as mudanças ocorridas na composição dos tecidos dos animais, com a redução do crescimento muscular e mais rápido desenvolvimento do tecido adiposo, em função do aumento no PCVZ, visto que o tecido adiposo tem maior impulso de crescimento em idades mais tardias (Berg \& Butterfield, 1979).

O conteúdo corporal de gordura em g/ $\mathrm{kg} \mathrm{PCVZ}$ para animais com peso vivo entre 250 e $450 \mathrm{~kg}$, é inferior aos obtidos por Lana (1991), com animais castrados em confinamento.

Os valores referentes às porcentagens de gordura no PCVZ, para animais de 400 a $450 \mathrm{~kg}$ de PV ( 343 e $397 \mathrm{~kg}$ PCVZ), foram de 21,7 e 27,8\%, evidenciando, dessa forma, que os animais em sistema de pastejo, neste estudo, exibiram bom acabamento da carcaça.

As equações de predição dos conteúdos de gordura, energia e proteína, por kg de ganho de PCVZ (Tabela 5), foram obtidas pela derivação das equações de regressão do logaritmo do conteúdo corporal de proteína, gordura e energia, em função do logaritmo do PCVZ.

As exigências líquidas de proteína e energia, bem como o conteúdo de gordura por $\mathrm{kg}$ de ganho de PCVZ e a relação G/PB no ganho, para animais mestiços Holandês-Zebu com pesos vivos entre 250 e $450 \mathrm{~kg}$, são apresentadas na Tabela 6 .

Como pode ser evidenciado na Tabela 6 , à medida que os pesos vivos dos animais se elevam, o conteúdo de gordura aumenta. Estes resultados concordam com os obtidos por Lana (1991), Pires et al. (1993 a,b), Fontes (1995) e Paulino (1996), os quais verificaram elevação nos ganhos de gordura com o aumento do PV de seus animais, que foram mantidos em condições de confinamento. 
Tabela 4 - Conteúdos corporais totais (kg) estimados de proteína (PBT) e gordura (GT), conteúdos de proteína e gordura (g) e energia (Mcal), por kg de peso corporal vazio, e relação entre conteúdos de gordura e proteína (G/PB), para novilhos mestiços castrados

Table 4 - Estimated total body contents of protein (TP) and fat (TF), protein and fat contents (g) and energy content (Mcal), per kg EBW, and fat/crude protein ratio of crossbreed steers

\begin{tabular}{|c|c|c|c|c|c|c|c|}
\hline \multirow{3}{*}{$\begin{array}{l}\text { PV } \\
L W \\
(\mathrm{~kg})\end{array}$} & \multirow{3}{*}{$\begin{array}{c}\text { PCVZ } \\
E B W \\
(\mathrm{~kg})\end{array}$} & \multirow{3}{*}{$\begin{array}{c}\text { PBT } \\
T P \\
(\mathrm{~kg})\end{array}$} & \multirow{3}{*}{$\begin{array}{c}\text { GT } \\
T F \\
(\mathrm{~kg})\end{array}$} & PB & $\mathrm{G}$ & $\mathrm{G} / \mathrm{PB}$ & \multirow{3}{*}{$\begin{array}{c}\text { Energia } \\
\text { Energy } \\
(\mathrm{Mcal} / \mathrm{kg} \mathrm{PCVZ}) \\
(\text { Mcal } / \mathrm{kg} E B W)\end{array}$} \\
\hline & & & & $C P$ & $F$ & $F / C P$ & \\
\hline & & & & \multicolumn{2}{|c|}{$\begin{array}{c}\text { (g/kg PCVZ) } \\
(g / k g E B W)\end{array}$} & & \\
\hline 250 & 179 & 34,9 & 13,1 & 195 & 73 & 0,374 & 1,72 \\
\hline 300 & 233 & 45,7 & 26,5 & 196 & 114 & 0,582 & 2,21 \\
\hline 350 & 288 & 56,8 & 46,7 & 197 & 162 & 0,822 & 2,71 \\
\hline 400 & 343 & 68,0 & 74,4 & 198 & 217 & 1,095 & 3,20 \\
\hline 450 & 397 & 79,0 & 109,9 & 199 & 277 & 1,391 & 3,67 \\
\hline
\end{tabular}

Tabela 5 - Equações de predição de ganho de proteína, gordura e energia por $\mathrm{kg}$ de ganho de peso do corpo vazio (GPCVZ) para novilhos mestiços castrados

Table 5 - Prediction equations of protein, fat and energy gain per $\mathrm{kg}$ of EBW gain for crossbreed steers

\begin{tabular}{|c|c|}
\hline $\begin{array}{l}\text { Componente } \\
\text { Component }\end{array}$ & $\begin{array}{l}\text { Equações de predição } \\
\text { Equations of predition }\end{array}$ \\
\hline Proteína ${ }^{1}$ & $\hat{\mathrm{Y}}=0,1747621 . \mathrm{PCVZ}^{0,026}$ \\
\hline Protein & \\
\hline Gordura $^{1}$ & $\hat{Y}=0,0000339 . P^{\prime} C^{1.669}$ \\
\hline Fat & \\
\hline Energia $^{2}$ & $\hat{\mathrm{Y}}=0,0241362 . \mathrm{PCVZ}^{0.9515}$ \\
\hline Energy & \\
\hline
\end{tabular}

Os dados referentes aos teores de proteína e gordura, no presente estudo, foram superiores aos obtidos por Lana (1991) e Fontes (1995), trabalhando com animais mestiços castrados, mantidos em confinamento. Os pequenos aumentos referentes às deposições de proteína, possivelmente se devem ao fato dos animais manifestarem ainda algum crescimento.

As exigências de energia líquida para ganho de $1 \mathrm{~kg}$ de peso de corpo vazio, para um animal de $400 \mathrm{~kg}$ de PV, foram superiores às obtidas por Lana (1991) e Fontes (1995), com animais confinados.

$\mathrm{Na}$ Tabela 7, são apresentadas as estimativas das

Tabela 6 - Conteúdos de gordura e exigências líquidas de energia e proteína por kg de ganho de PCVZ e relação gordura/ proteína (G/PB) no ganho de animais mestiços castrados

Table 6 - Contents of fat and net energy and protein requirements per $\mathrm{kg}$ of gain and fat/crude protein ratio of crossbreed steers

\begin{tabular}{cccccc}
\hline $\begin{array}{c}\text { PV }(\mathrm{kg}) \\
L W\end{array}$ & $\begin{array}{c}\text { PCVZ }(\mathrm{kg}) \\
E B W\end{array}$ & $\begin{array}{c}\text { Gordura } \\
\text { Fat } \\
\text { (g/kg GPCVZ) } \\
\text { (g/kg EBW gain) }\end{array}$ & $\begin{array}{c}\text { Energia } \\
\text { Energy } \\
\text { (Mcal/kg GPCVZ) } \\
\text { (Mcal/kg EBW gain) }\end{array}$ & $\begin{array}{c}\text { Proteína } \\
\text { Protein } \\
\text { (g/kg GPCVZ) } \\
\text { (g/kg EBW gain) }\end{array}$ & $\begin{array}{c}\text { Relação } \\
\text { G/PB } \\
\text { F/P }\end{array}$ \\
\hline 250 & 179 & 196 & 3,36 & 200 & 0,98 \\
300 & 233 & 304 & 4,32 & 201 & 1,51 \\
350 & 288 & 432 & 5,28 & 202 & 2,14 \\
400 & 343 & 579 & 6,24 & 203 & 2,85 \\
450 & 397 & 739 & 7,17 & & 3,62 \\
\hline
\end{tabular}


exigências líquidas de energia e proteína, para ganho de $1 \mathrm{~kg}$ de peso vivo.

Considerando um animal de $300 \mathrm{~kg}$ de PV, com eficiência de utilização de energia para ganho em torno de $40 \%$, tem-se um valor de aproximadamente $3,26 \mathrm{~kg} \mathrm{NDT} / \mathrm{kg}$ de ganho.

Tabela 7 - Estimativas das exigências líquidas de energia e proteína por $\mathrm{kg}$ de ganho de peso vivo de animais mestiços castrados, em função do peso vivo (PV) ou do peso de corpo vazio (PCVZ)

Table 7 - Net requirements estimated of energy and protein per $K g L W$ gain for crossbreed steers, in function of $L W$ or $E B W$

\begin{tabular}{lccc}
\hline PV $(\mathrm{kg})$ & $\begin{array}{c}\text { PCVZ }(\mathrm{kg}) \\
L W\end{array}$ & $\begin{array}{c}\text { Proteína }(\mathrm{g}) \\
\text { Protein }\end{array}$ & $\begin{array}{c}\text { Energia }(\text { Mcal }) \\
\text { Energy }\end{array}$ \\
\hline 250 & 179 & 217 & 3,65 \\
300 & 233 & 218 & 4,70 \\
350 & 288 & 220 & 5,74 \\
400 & 343 & 221 & 6,78 \\
450 & 397 & 222 & 7,79 \\
\hline
\end{tabular}

\section{Conclusões}

A suplementação concentrada no período das águas não influenciou os conteúdos corporais de proteína, gordura e energia para ganho de peso. As exigências líquidas de proteína e energia para um animal de $350 \mathrm{~kg}$ de peso vivo foram, respectivamente, de 220 g e 5,74 Mcal por kg ganho de peso vivo.

\section{Literatura Citada}

AGRICULTURAL AND FOOD RESEARCH COUNCIL AFRC. Technical committee on responses to nutrients, Report 9. Nutritive requirements of ruminant animals: protein. Nutrition Abstract Review, v.62, n.12, p.787-835, 1993.

AGRICULTURAL RESEARCH COUNCIL - ARC. The nutrient requirements of ruminants livestock. London: Commonwealth Agricultural Bureaux, 1980.351p.

AGRICULTURAL RESEARCH COUNCIL - ARC. The nutrient requirements of ruminants livestock. Report of the protein group of the Agricultural Research Council Working Party on the nutrient requirements of ruminants. London: 1984. (Supplement 1)

BERG, R.T.; BUTTERFIELD, R.M. El crescimiento del ganado vacuno y la producción de carne de vacuno In: NUEVOS conceptos sobre desarrollo de ganado vacuno. Zaragoza: Acribia, 1979. p.16-29.

CAMPOS, J. Tabelas para cálculo de rações. 2.ed. Viçosa, MG: Universidade Federal de Viçosa, 1995. 64p.
COELHO DA SILVA, J.F. Exigências de macroelementos inorgânicos para bovinos: o sistema ARC/AFRC e a experiência no Brasil. In: SIMPÓSIO INTERNACIONAL SOBRE EXIGÊNCIAS NUTRICIONAIS DE RUMINANTES, 1995, Viçosa. Anais... Viçosa, MG: Universidade Federal de Viçosa, 1995. p.467-504.

FONTES, C.A.A. Body composition, net requeriments of protein, energy and minerals for weight gain and productive performance of Zebu and crossbred European-Zebu cattle. In: SIMPÓSIO INTERNACIONAL SOBRE EXIGÊNCIAS NUTRICIONAIS DE RUMINANTES, 1995, Viçosa, MG. Anais... Viçosa, MG: Universidade Federal de Viçosa, 1995. p. $265-300$.

HANKINS, O.G.; HOWE, P.E. Estimation of the composition of beef carcasses and cuts. Washington, D.C: 1946 . (Tech. Bulletin - USDA, 926).

HESS, B.W.; KRYSL, L.J.; JUDKINS, M.B. et al. Supplemental corn or wheat bran for steers grazing endophyte-free fescue pasture: effects on live weight gain, nutrient quality, forage intake, particulate and fluid kinetics, ruminal fermentation, and digestion. Journal of Animal Science, v.74, p.11161125, 1996.

JORGE, A.M. Desempenho produtivo, características e composição corporal e da carcaça de zebuínos de quatro raças, abatidos em diferentes estágios de maturidade. Viçosa, MG: Universidade Federal de Viçosa, 1997. 99p. Tese (Doutorado em Zootecnia) - Universidade Federal de Viçosa, 1997.

KOCK, S.W.; PRESTON, R.L. Estimation of bovine carcass composition by the urea dilution technique. Journal of Animal Science, v.48, n.2, p.319-327, 1979.

KÖEPEN, W. Climatologia. Buenos Aires: Gráfica Panamericana, 1948. 478p.

LANA, R.P. Composição corporal e exigências de energia, proteína e macroelementos minerais (Ca, P, Mg, $\mathrm{Na} \mathrm{e} \mathrm{K)}$ de novilhos de cinco grupos raciais, em confinamento. Viçosa, MG: Universidade Federal de Viçosa, 1991. 134p. Dissertação (Mestrado em Zootecnia) - Universidade Federal de Viçosa, 1991.

MERTENS, D.R. Regulation of forage intake. In: Forage quality, evaluation and utilization. FAHEY Jr., G.C. (Ed.) Madison: American Society of Agronomy, 1994. p.59-114.

NATIONAL RESEARCH COUNCIL - NRC. Nutrient requirements of beef cattle. 6.ed. Washington, D.C: 1984.90 p.

NATIONALRESEARCHCOUNCIL-NRC. Nutrient requirements of beef cattle. 7.ed. Washington, D.C: 1996. 243p.

NOLLER, C.H.; NASCIMENTO Jr., D.; QUEIROZ, D.S. Exigências nutricionais de animais em pastejo. In: SIMPÓSIO SOBRE MANEJO DE PASTAGEM, 13., 1996, Piracicaba. Anais... Piracicaba: Fundação de Estudos Agrários "Luiz de Queiroz", 1996. p.151-184.

PAULINO, M.F. Composição corporal e exigências de energia, proteína e macroelementos minerais (Ca, $\mathrm{P}, \mathrm{Mg}, \mathrm{Na}$, K) de bovinos não castrados de quatro raças zebuínas em confinamento. Viçosa, MG: Universidade Federal de Viçosa, 1996. 80p. Tese (Doutorado em Zootecnia) - Universidade Federal de Viçosa, 1996.

PAULINO, M.F. Suplementos múltiplos para recria e engorda de bovinos em pastagens. In: CONGRESSO NACIONAL DOS ESTUDANTES DE ZOOTECNIA, 1998, Viçosa. Anais... Viçosa, MG: Associação Mineira dos Estudantes de Zootecnia, 1998. p.173-188.

PENATI, M.A.; CORSI, M.; MARTHA JR., G.B. et al. Manejo de plantas forrageiras no pastejo rotacionado. In: SIMPÓSIO 
GOIANO SOBRE PRODUÇÃO DE BOVINOS DE CORTE, Goiânia, 1999. Anais... Goiânia: Colégio Brasileiro de Nutrição Animal, 1999. p.123-144.

PIRES,C.C.; FONTES, C.A.A.; GALVÃO, J.G. et al. Exigências nutricionais de bovinos de corte em acabamento. I. Composição corporal e exigências de proteína para ganho de peso. Revista da Sociedade Brasileira de Zootecnia, v.22, n.1, p.110-120, 1993a.

PIRES,C.C.; FONTES, C.A.A.; GALVÃO, J.G. et al. Exigências nutricionais de bovinos de corte em acabamento. II. Exigências de energia para mantença e ganho de peso.Revista da Sociedade Brasileira de Zootecnia, v.22, n.1, p.121-132, 1993 b.

REGAZZI, A.J. Teste para verificar a identidade de modelos de regressão e a igualdade de alguns parâmetros num modelo polinomial ortogonal. 1993. Revista Ceres, v.40, n.228, p.176-195, 1993

SANCHES, L.T.T., NASCIMENTO JR., D., DIOGO, J.M.S. et al. Composição química da forragem disponível versus dieta de bovinos em pastagem natural. Revista Brasileira de Zootecnia, v.22, n.5, p.852-861, 1993.
SILVA, D.J. Análise de alimentos: métodos químicos e biológicos. Viçosa, MG: Universidade Federal de Viçosa, 1990. 165p.

SNIFFEN, C.J.; O'CONNOR, J.D.; VAN SOEST, P.J. et al. A net carbohydrate and protein sytem for evaluating cattle diets: II - Carbohydrate and protein availability. Journal Animal Science, v.70, p.3562-3577, 1992.

UNIVERSIDADE FEDERAL DE VIÇOSA - UFV. SAEG Sistema de análises estatísticas e genética. Viçosa, MG: 1995. (Apostila).

Van SOEST, P.J.; ROBERTSON, J.B.; LEWIS, B.A. Methods for dietary fiber, and nonstarch polysaccharides in relation to animal nutrition. Journal of Animal Science, v.74, n.10, p.3583-3597.

Recebido em: $17 / 08 / 00$ Aceito em: 10/08/01 